\title{
Amoxicillin induced toxic epidermal necrolysis
}

\author{
Lakshmi Narasimha G.*, Kalpana P.
}

Department of Pharmacy Practice, Annamacharya College of Pharmacy, Rajampeta, Kadapa, Andhra Pradesh, India

Received: 02 January 2020

Accepted: 11 February 2020

\section{*Correspondence:}

Dr. Lakshmi Narasimha G.,

Email: gunturunarasimha007@gmail.com

Copyright: (c) the author(s), publisher and licensee Medip Academy. This is an open-access article distributed under the terms of the Creative Commons Attribution Non-Commercial License, which permits unrestricted non-commercial use, distribution, and reproduction in any medium, provided the original work is properly cited.

\begin{abstract}
Toxic epidermal necrolysis (TEN) is a rare life-threatening adverse drug reaction associated with mucocutaneous eruptions and peeling of skin (sloughing) mostly caused by drugs like sulphonamides, beta lactams, carbamazepine and non-steroidal anti-inflammatory drugs (NSAIDs). Amoxicillin is a broad spectrum, bactericidal, Beta-lactam antibiotic used in treatment of various infections. Here by we have reported the case of amoxicillin induced severe toxic epidermal necrolysis. A Patient admitted in the hospital with the symptoms of epidermal sloughing that resulted in bare dermis as he received Amoxicillin drug for his diagnosis of fever. After clear examination TEN was confirmed and suspected with the cause due to Amoxicillin. The drug was stopped and patient was treated with other drugs for symptomatic cure. The patient was recovered from his condition and improved significantly.
\end{abstract}

Keywords: Amoxicillin, Adverse drug reactions, Life threatening, Mucocutaneous eruptions, Skin sloughing, Toxic epidermal necrolysis

\section{INTRODUCTION}

Amoxicillin is a broad spectrum, bactericidal and a beta lactam antibiotic that is used in treatment of various infections. The most important concern regarding the use of antibiotics is the occurrence of adverse drug reactions. These reactions appear in the form of drug eruptions on the skin as maculopapular rashes, urticarial eruptions, serum sickness like reactions (SSLR), blisters formation and bullous erythema etc. Toxic epidermal necrolysis (TEN) is the serious life-threatening drug eruption associated with the use of amoxicillin. ${ }^{1}$ It is characterised by epidermal sloughing, blisters and mucocutaneous reactions. Drug and its metabolites are the main cause for the development of TEN. The following drugs were reported with TEN like sulphonamides, allopurinol, carbamazepine, phenobarbital, nevirapine, penicillin and non-steroidal anti- inflammatory drugs (NSAIDs) etc. ${ }^{2}$

\section{CASE REPORT}

A 22 years old male was admitted in the Government General Hospital, Kadapa with complaints of Sloughing of skin, small blisters on the trunk and four limbs with presence of burning sensation all over the body (Figure 1 and 2). He was diagnosed with fever for last three days and received tablet amoxicillin-clavulanic acid and injection amoxicillin sodium as initial drug treatment with the dose of $625 \mathrm{mg}$ and $250 \mathrm{mg}$ twice daily respectively. Complaints developed after administering of those drugs for fever within three days. During his admission, after clear examination it was found that the lesions are erythematous macular lesions with darker haemorrhagic pattern all over the body and dislodgment of epidermis on the limb region. No mucosal and genital involvement. Nikolsky's sign was positive. The condition was diagnosed as drug induced TEN and the suspecting drug was amoxicillin as causative by the dermatologist. Except the skin lesions rest of the findings were normal. Laboratory investigation were $\mathrm{Hb}-10.5 \mathrm{gm} \%$, TC- 1200 
cells/cu mm, RBS- $84 \mathrm{gm} / \mathrm{dl}$, blood urea nitrogen- 20 $\mathrm{mg} / \mathrm{dl}$, bicarbonates- $23 \mathrm{mEq} / \mathrm{l}$, platelet- 2.0 lakhs, serum glucose- $110 \mathrm{mg} / \mathrm{dl}$, liver function tests and renal function tests were normal.

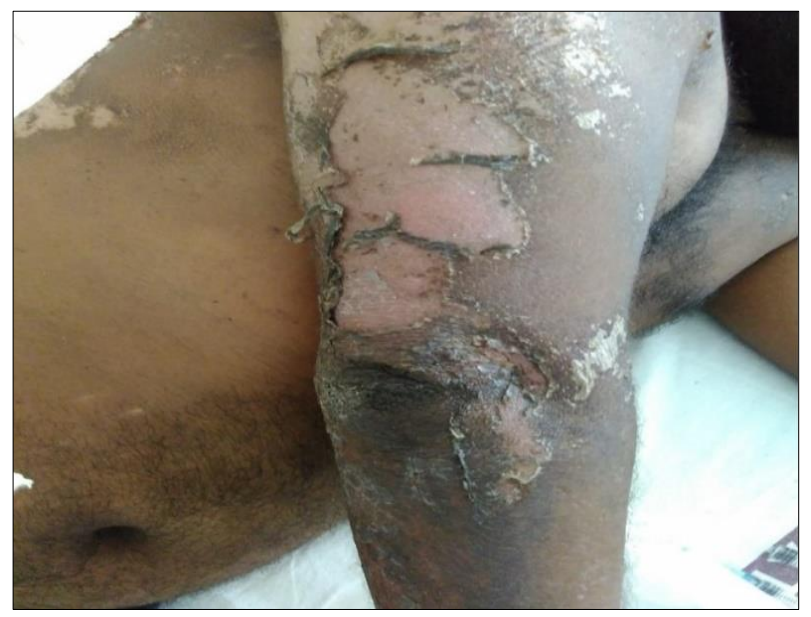

Figure 1: Peeling of skin on the elbow a condition of toxic epidermal necrolysis.

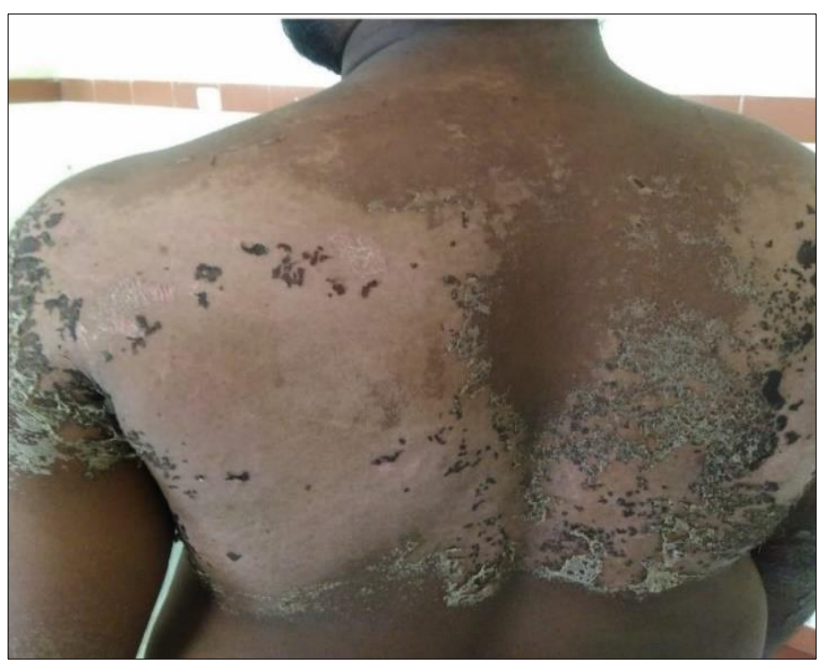

Figure 2: Sloughing of skin on upper back of body due to toxic epidermal necrolysis.

\section{Outcome and follow-up}

After suspecting the condition patient was advised to stop Amoxicillin and started treatment for TEN. He was prescribed with dexamethasone injection $2 \mathrm{cc}$, pheniramine maleate injection $2 \mathrm{cc}$, promethazine injection $25 \mathrm{mg}$, silver sulfasalazine ointment and fusidic ointment for topical application. After one week of treatment the patient showed significant improvement in his condition and got discharged.

\section{DISCUSSION}

Cutaneous drug eruptions are the most commonly reported adverse drug reactions. Although TEN was rare with severe form of erythema it was important to recognize the clinical characteristics of eruptions at an early stage due to high mortality rate which ranges from $16-25 \% .^{3}$ In this case report TEN was observed after the initiation of amoxicillin treatment. Then after the withdrawal of amoxicillin TEN symptoms were slowly normalised and improved Patient condition. In many case reports it was observed that Amoxicillin is the causative agent for the TEN. ${ }^{4}$ TEN is caused mostly by the antibiotics and its estimated probability was found to be nearly $49 \%$ associated with the antibiotic use in the clinical settings. ${ }^{5}$ It starts with the acute phase with the involvement of clinical features like fever and discomfort with swallowing fallowed by the cutaneous manifestations like epidermal sloughing on trunk, face, palms and soles and this peeling of skin contributes to $>30 \%$ of body surface area in case of TEN. ${ }^{6}$ This condition involves the apoptosis of keratinocytes by two pathways like intrinsic pathway and extrinsic pathway which involves the apoptosis inducing factors like reactive oxygen species, $\mathrm{TNF} \alpha$, Interleukin-2, cytotoxic proteins like granulising and perforin-granzyme. ${ }^{7}$ Other existing evidences suggest that this condition was also associated with the dermal sweat duct alterations and vaculopathy but there were no alterations in this case were reported. ${ }^{8}$ We calculated the SCORETEN score for this patient to estimate severity of illness and he was found to be only associated with only one risk factor that is $>10 \%$ of epidermal detachment hence obtained the score of 1 point that shows less significant mortality of $3.2 \%$ in this reported case as he was just in the acute or initial stage of the condition but whereas score of 5 or $>5$ shows high mortality rate of $90 \%$.

\section{CONCLUSION}

Skin is mostly involved in the drug induced hypersensitivity reactions and the conditions like TEN were proved to be life threatening. Therefore Health care Professionals need to educate public regarding the offending drugs that causes Hypersensitivity reactions like TEN. This Knowledge will be useful to identify and report such events as a part of Pharmacovigilance.

Funding: No funding sources

Conflict of interest: None declared

Ethical approval: Not required

\section{REFERENCES}

1. Helen T Shin, Mary Wu Chang. Drug Eruptions in Children. Curr Probl Pediatr. 2001;31:207-34.

2. Harris V, Jackson C, Cooper A. Review of Toxic Epidermal Necrolysis. Int J Mol.Sci. 2016;17:1-10.

3. Zachariah TG, Rao KNS, Noronha TM, Acharya S, Pooja M, Noble J. Amoxicillin induced toxic epidermal necrolysis. Int J Basic Clin Pharmacol. 2016;5(3):1134-37.

4. Pathak S, Nagar M, Kavad M, Patel H, Patel K, Patel M. Single dose amoxicillin induced toxic epidermal 
necrolysis-A rare life threatening dermatological condition. Inter Arch Integrat Med. 2016;3(4):18790.

5. Yang SC, Sindy Hu, Zhang SZ, Huang J, Zhang J, Ji $\mathrm{C}$, et al. The Epidemiology of Stevens-Johnson Syndrome and Toxic Epidermal Necrolysis in China. J Immunol Res. 2018;(6):1-10.

6. Harr T, French LE. Toxic epidermal necrolysis and Stevens-Johnson syndrome. Orphanet J Rare Dis. 2010;5(39):1-11.
7. Kinoshita Y, Saeki H. A review of the pathogenesis of toxic epidermal necrolysis. J Nippon Med School. 2016;83(6):216-22.

8. Ramdial PK, Naidoo DK. Drug-induced cutaneous pathology. J Clini Pathol. 2009;62(6):493-504.

Cite this article as: Narasimha GL, Kalpana P.

Amoxicillin induced toxic epidermal necrolysis. Int J Basic Clin Pharmacol 2020;9:510-2. 